\title{
DEFORMIDADE CRANIANA APÓS IMPLANTAÇÃO DE SISTEMA DE DERIVAÇÃO VENTRICULAR COM VÁLVULA
}

\author{
João P. Barile*, Prof Dr. Enrico Ghizoni.
}

\begin{abstract}
Resumo
A derivação ventrículo-peritoneal (DVP) é o principal procedimento utilizado no tratamento de pacientes portadores de hidrocefalia, em especial durante o primeiro ano de vida. Em situações especiais, podem ser utilizados outros procedimentos como derivação ventrículo-atrial (DVA), derivação ventrículo sub-galeal, ou neuroendoscopia. Contudo, apesar de altamente eficaz no tratamento da hidrocefalia, as derivações ventriculares possuem uma alta taxa de complicações (5 a 30\%) que incluem principalmente disfunções mecânicas e infecções. Objetivo: investigar a prevalência de deformidade ao uso de derivação ventricular, padrão da deformidade, taxa de complicações e potenciais causas. Métodos: estudo transversal retrospectivo de todas as crianças que foram submetidas à implantação de um sistema de derivação ventricular durante o primeiro ano de vida, procedimentos realizados nos últimos 11 anos (2004 a 2015), no Hospital das Clínicas da Universidade de Campinas e no Centro de Atenção Integral à Saúde da Mulher (CAISM) da Universidade Estadual de Campinas. Resultados: 50 pacientes do sexo masculino $(58,13 \%), 36$ pacientes do sexo feminino, idade média na primeira cirurgia de 43,62 dias, média de cirurgia de shunt/paciente de 1,91. Conclusões: Conclui-se que hidrocefalia é causada por diversas etiologias e o tratamento cirúrgico definitivo prioritário é a DVP, nos pacientes submetidos à cirurgia no 1ํan ano de vida, possuem relativamente alta taxa de complicações (33,93\%), com necessidade de troca a cada de sistema de derivação a cada 1,91 paciente.
\end{abstract}

\section{Palavras-chave:}

hidrocefalia, derivação, neurocirurgia pediátrica .

\section{Introdução}

A derivação ventrículo-peritoneal (DVP) é o principal procedimento utilizado no tratamento de pacientes portadores de hidrocefalia, em especial durante o primeiro ano de vida ${ }^{1}$. Apesar de altamente eficaz no tratamento da hidrocefalia, as derivações ventriculares possuem uma alta taxa de complicações (5 a 30\%), principalmente disfunções mecânicas e infecções ${ }^{1,2,3,4}$.

O objetivo do trabalho é investigar a prevalência de deformidade ao uso de derivação ventricular, taxa de complicações e potenciais causas.

\section{Resultados e Discussão}

Trata-se de um estudo transversal retrospectivo, incluindo todas as crianças submetidas à derivação ventricular definitiva (DVP/DVA) com idade inferior a um ano de vida, durante o período de 2004 até 2015, com análise dos prontuários dos pacientes submetidos a tais cirurgias nos hospitais HC-UNICAMP e CAISM. Foram analisados 115 pacientes operados nos dois serviços, 51 no HCUNICAMP (11 tiveram a $1^{\underline{a}}$ cirurgia no CAISM, 9 tiveram a $1^{\text {a }}$ cirurgia em outro serviço, 5 prontuários com dados faltantes, totalizando 26$)$ e 64 no CAISM (100\% tiveram a $1^{\text {a }}$ cirurgia no CAISM, 3 prontuários com dados faltantes, totalizando 61). No total (HC-UNICAMP e CAISM), temos 87 pacientes: 50 sexo masculino $(58,13 \%), 36$ do sexo feminino, idade média na primeira cirurgia de 43,62 dias, média de cirurgia de shunt/paciente de 1,91 (Fig 1). Além disso, o diagnóstico de hidrocefalia foi realizado na presença de alteração de exame de imagem $(n=65$; $71,42 \%$ ) ultrassonografia (principalmente) e de tomografia, sinais e sintomas de macrocrania ( $n=47,51,64 \%)$, irritabilidade ( $n=12 ; 13,18 \%)$, vômitos $(n=5 ; 5,49 \%)$, fontanela tensa e abaulada ( $n=9 ; 9,89 \%)$. Entre os 87 casos, 18 possuem etiologia adquirida (20,69\%) e 69 congênita $(79,31 \%)$. As causas congênitas mais comuns são mielomeningocele $(n=29,42 \%)$, corpo caloso $(n=6$, 8,69\%), Síndrome Dandy-Walker ( $n=6,8,69 \%)$, todavia há grande número de idiopáticos $(n=20,28,98 \%)$. Entre as adquiridas, a maioria por hemorragia $(n=11,61,11 \%)$, seguida de infecção $(n=5,27,77 \%)$, de TORCHES $(n=1$, $5,55 \%)$ e de prematuridade sem sangramento $(n=1$, $5,55 \%)$. Há alta incidência de complicações $(n=33,93 \%)$, principalmente mecânicas $(n=25)$ e, com menor frequência, infecciosas ( $n=14,100 \%$ de meningite), com 7 casos com ambas complicações. Entre as mecânicas, são obstrutivas $(n=14,56 \%)$ e hiperdrenagem $(n=8,32 \%)$.

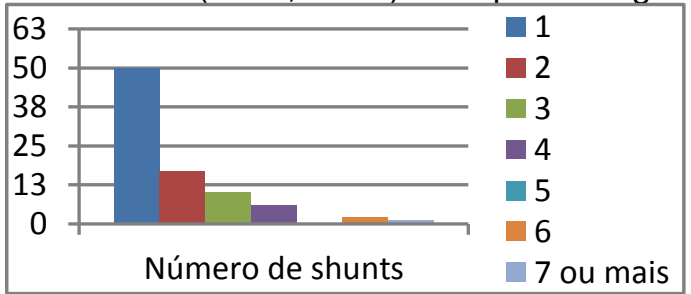

Figura 1: quantidade de cirurgias de shunt

\section{Conclusões}

Conclui-se que hidrocefalia no $1^{\circ}$ ano de vida tem como etiologia principal mal formações congênitas e o tratamento cirúrgico definitivo foi a DVP. Pode se perceber que pacientes submetidos à DVP no $1^{\circ}$ ano de vida apresentaram alta taxa de complicações $(33,93 \%)$, com média de cirurgia de shunt/paciente de 1,91.

\section{Agradecimentos}

Agradeço ao SAE/PIBIC-UNICAMP pelo apoio à pesquisa.

[1]Cunha,AHGB.Rev Bras de Neurol e Psiq, v18, n2, p.85-93. 08/2014. [2]Tully, H. J Child Neurol;31(3):309-32,03/2016. [3]Paulsen,AH.JNeurosurg Pediatr 16:633641,09/2015; [4]Esther B. Dupepe, E. Neurosurg Focus. 41(5): E6, 11/2016. 